ConNotas. Revista de crítica y teoría literarias / Vol. V, Núm. 9 / 2007

\title{
Hermenéutica y construcción de la identidad cultural en El coronel no tiene quien le escriba
}

\author{
ElizABETH HeRnÁNDEZ AlvíDREZ*
}

\section{Resumen:}

El presenta artículo plantea la reincorporación a la discusión pedagógica de la literatura como fuente de conocimiento, esto a modo de respuesta al agotamiento de la educación de corte ilustrado que privilegia el racionalismo y, como consecuencia, relega la formación del pensamiento creativo propio de las manifestaciones artísticas. En Latinoamérica, la narrativa acoge en su interior las diversas voces de un conflicto que se ha gestado en la historia y permite la presencia de espacios y tiempos que son negados por la modernidad ilustrada. A través de un ejercicio hermenéutico tal y como lo entienden tanto Gadamer como Paul Ricoeur, es posible encontrar dichos espacios negados, con el propósito de colmar los vacíos de una imagen identitaria que, en virtud de una tendencia monolítica, rechaza las expresiones de la heterogeneidad. Una lectura de este tipo de El coronel no tiene quien le escriba (1961), de Gabriel García Márquez, permite el hallazgo de una identidad más acorde a la realidad latinoamericana.

\section{Palabras clave:}

Heterogeneidad, modernidad, Gadamer, Ricoeur, pedagogía, racionalismo, Latinoamérica, García Márquez. 


\section{Introducción}

El principio de investigación que sustenta este trabajo consiste en que algunas obras de la narrativa latinoamericana contemporánea constituyen una vía para trabajar educativamente una formación crítica de la identidad cultural. Asimismo, se parte de la reincorporación de la literatura como fuente de conocimiento en la discusión pedagógica a manera de respuesta al agotamiento de la educación de corte ilustrado que relega la formación del pensamiento creativo propio de las manifestaciones artísticas, y privilegia el pensamiento lógico con la ciencia y la tecnología. Para desarrollar esta idea, iniciaré con la presentación resumida de los fundamentos que establecen la relación entre hermenéutica literaria y educación. Una segunda parte del trabajo está dedicada a explicitar el sentido de la identidad cultural que revela la hermenéutica literaria en Latinoamérica; por último, en la tercera parte, presento, a manera de ejemplificación, una interpretación de la novela El coronel no tiene quien le escriba (1974), de Gabriel García Márquez.

\section{Hermenéutica y educación}

La filosofía hermenéutica establece principios para una concepción de educación mediante el estudio del lenguaje simbólico. Específicamente, sirven a estos propósitos las hermenéuticas de Hans Georg Gadamer y Paul Ricoeur. La hermenéutica de la comprensión de la tradición desarrollada por Gadamer, así como la categoría humanista de formación (Bildung), ofrecen un concepto de educación como práctica mediadora de la cultura que, en cuanto tradición, se considera a su vez una mediación del presente con el pasado; esto ocurre a través de los productos culturales, como las obras literarias, que constituyen un legado donde se decanta la reflexión humana. La incorporación de la hermenéutica de Gadamer a la investigación pedagógica abre no sólo la crítica a la educación positivista, sino que también propone la formación de la cultura mediante los productos artísticos como portadores de tradición, para 
reconocer en ellos una identidad que se traduzca en una actitud ética de saber actuar en la vida.

Por otra parte, en la hermenéutica reflexiva, Ricoeur une literatura y filosofía, ya que plantea la formación de un sujeto crítico que se autocuestiona en la interacción simbólica con los textos literarios, conjuntando la crítica de la ideología y la confianza en la tradición. El aporte específico de Ricoeur es su trabajo sobre el texto narrativo como el texto por excelencia, pues revela la historia de la vida social e individual, la humanización del tiempo y la descripción de las experiencias y preocupaciones humanas. La realidad o campo práctico, dice Ricoeur, es una primera instancia de mediación simbólica que le sirve al texto como prefiguración referencial. La obra narrativa es una configuración que pasa por la precomprensión o prefiguración, es decir, el texto narrativo es una mediación simbólica construida a partir de otra mediación simbólica que le antecede. El acto de lectura es una tercera mediación que vuelve a la primera (mundo de la acción) a través de la segunda (mundo de la obra), en un acto espiral, que consiste en una nueva mirada refiguradora que puede enriquecer el criterio y modificar el actuar en la vida. La obra narrativa hace inteligibles las preocupaciones humanas de la vida práctica. La narración tiene sentido completo cuando regresa al mundo de la acción gracias a un acto de lectura.

Tomando en cuenta las relaciones entre hermenéutica, literatura y educación, podemos considerar que una vía para la hermenéutica de la identidad cultural latinoamericana es su literatura. La visión de mundo manifestada en la producción literaria latinoamericana permitiría la formación de una base cultural crítica respecto del mundo de vida que deseamos. La propuesta concreta que formulo para el campo educativo consiste en la formación de un lector con competencia hermenéutica que, en la interpretación de textos literarios construya su identidad colectiva.

Esta fundamentación nos puede guiar para trabajar la hermenéutica del contexto latinoamericano mediante el análisis del papel formador de la conciencia identitaria que se presenta como potencial en la literatura narrativa, con las categorías hermenéuticas específicas requeridas para la interpretación de estos textos. El traba- 
jo hermenéutico consiste en la recuperación de la memoria cultural relegada o reprimida que permanece latente con gran vitalidad y ha sido fuente de varios textos narrativos de la literatura latinoamericana.

\section{Hermenéutica literaria y construcción de la identidad cultural}

En seguimiento de los planteamientos enunciados en el parágrafo anterior, presento a continuación algunas líneas de reflexión con el fin de proponer una orientación del análisis literario correspondiente a un tipo de lector que accede a la obra en un nivel tal de interlocución con el texto que le posibilita la formación para la crítica y la construcción de la identidad en el contexto latinoamericano actual, en el marco específico del debate de la multiculturalidad en la modernización. Con ello he llevado al plano de la aplicación en el análisis literario las reflexiones realizadas en el campo de la filosofía de la cultura acerca del papel de la ficción literaria en la formación de la identidad cultural (Hernández).

Para comprender el conflicto de la crítica de la identidad en Latinoamérica, son útiles dos claves hermenéuticas: la primera, procedente de la hermenéutica de Hans Georg Gadamer; es la necesidad de revalorar el mito, que ha perdurado, entre otros lugares, en la ficción literaria, como complemento del pensamiento conceptual, para reunir las partes fragmentadas por el predominio de la racionalidad lógica; la segunda, procedente de la hermenéutica de Paul Ricoeur, es la configuración de la identidad como narratividad construida, no sólo por la Historia, sino también por la literatura.

Existen dos posibilidades para la hermenéutica de la identidad en los textos literarios desde la perspectiva planteada: una que corresponde al receptor y otra a la obra; la primera consiste en partir de una concepción de la lectura como acto ético que tiene efectos en el lector como sujeto que interactúa en una relación de sujeto a sujeto con la obra, y la segunda es el carácter polifónico de la narrativa. Una concepción de la lectura como la que propongo está fundamentada por el enfoque hermenéutico de la teoría de la recepción, en la que he seguido principalmente a Hans Robert Jauss, ya 
que permite hacer inferencias a los efectos de la experiencia estética en el lector, en la comprensión del texto y en el re-conocimiento de la realidad implicado en la interpretación de la obra. Por otra parte, la polifonía, concepto aportado por la teoría de Mijaíl Bajtín, de cierta narrativa latinoamericana, que incorpora estructuralmente la participación dialógica de diferentes voces portadoras de ideas sobre la realidad, abre la posibilidad de atender la multiculturalidad en los textos literarios para apoyar la hermenéutica de la identidad, pues la polifonía como categoría de análisis de la cultura latinoamericana ha dado frutos interpretativos en el campo de las artes, la literatura y la filosofía de la cultura.

Asimismo, la interpretación de la identidad en el texto de creación se logra gracias al giro dado en el campo literario: del análisis circunscrito en la inmanencia de la obra hacia los estudios culturales, que toman en cuenta la referencia de la ficción a la realidad y que son reveladores tanto de la manera en que la literatura representa los conflictos de la identidad en Latinoamérica como de las formas en que la literatura latinoamericana ha llegado a producir una expresión original de una particularidad cultural, de acuerdo con factores socio-históricos específicos. De esta manera, considero que la literatura es una vía para dar sentido a la vida, mediante la posibilidad de una autocrítica, sólo posible a través de una orientación de la lectura como acto ético que, latente en los estudios literarios mencionados, cobra cabal sentido en un enfoque filosófico como el de la hermenéutica.

La pregunta por la identidad ${ }^{1}$ en gran parte de la literatura latinoamericana producida desde mediados del siglo XX puede estu-

\footnotetext{
${ }^{1}$ Después de haber referido varias veces el término de identidad cultural, considero adecuado aclarar que el concepto de identidad, o reconocimiento de los otros como idénticos a uno mismo por sus prácticas, lo considero no como esencia, sino como la condición de ser humano en un contexto espacio-temporal específico. La identidad latinoamericana se entiende así como la comunidad que puede establecerse actualmente entre los diversos pueblos que comparten factores históricos como los siguientes:

- Un pasado que determinó la convivencia de varios sustratos, como las culturas
} 
diarse y responderse a través de la crítica de los esquemas culturales organizadores del mundo de la vida en la época actual. La presencia de la multiculturalidad de las visiones de mundo es una respuesta al univocismo de la modernización.

Una lectura dinámica permite atender la invocación del pasado en la obra y exige la participación del receptor, que ayuda al autor a buscar la identidad múltiple. La obra latinoamericana reúne la visión antigua con la nueva, la visión mítica con la moderna. En Latinoamérica, una fuerza cultural creadora incorpora en la narrativa literaria las diversas voces de un conflicto que se ha gestado en la historia y permite la presencia de espacios y tiempos que son negados, rechazados por la modernidad ilustrada.

Un paradigma cultural desplazado es el pensamiento mítico, en el que los problemas humanos se recrean por la vía de la experiencia del cuerpo en relatos que, a través de imágenes, conducen a los símbolos. La búsqueda de la restauración de la conciencia mítica como forma del re-ligamiento por medio de los símbolos, que le da seguridad al ser humano de su lugar en el cosmos y en la comunidad de los semejantes, es una de las constantes de estas obras, como presencia de la multiculturalidad.

indígenas, y las europeas, orientales y africanas que llegaron a América por medio de la colonización ibérica.

- Un lenguaje que, entendido en su interacción con las visiones de mundo, ha madurado en lenguas de expresión de una manera de ser característica de este contexto, al apropiarse de las múltiples herencias lingüísticas de los sustratos mencionados.

- La influencia de un modo de confluencia de este multiculturalismo particular, ante la hegemonía de la visión de mundo europea y como resultado de condiciones socioeconómicas, además de las culturales, que ubican a estos pueblos en circunstancias semejantes, definidas por una disonancia respecto de otras visiones de mundo como las de la modernización.

- El resurgimiento de estas visiones de mundo en condiciones similares de imposición de modelos de vida, con la globalización, desacordes con otras formas de concebir el sentido de la vida.

- El surgimiento de una producción literaria original que posibilita la muestra de cosmovisiones subvaloradas por la cultura dominante. 


\section{El conflicto entre modernidad y tradición en El coronel no tiene quien le escriba}

Para estudiar la presencia del mito en la literatura latinoamericana, he procedido al análisis hermenéutico de algunas obras, como las de Gabriel García Márquez. Sus textos incorporan el pensar mítico, como lo llama Ángel Rama, no sólo temática sino estructuralmente. Esta característica tiene consecuencias en la lectura como proceso de construcción de la identidad, pues el lector no sólo tiene que interpretar el contenido temático de los mitos, sino que el modo de lectura requerido es el del seguimiento del ritual, basado en la narración de las acciones del héroe.

Por ejemplo, hay algún tipo de viaje en el que el héroe enfrenta un conflicto, como la lucha con los discursos que lo encierran. En la novela El coronel no tiene quien le escriba, el personaje central referido en el título hace un viaje interno de la decepción hacia la esperanza, paralelo a su recorrido en el espacio de su comunidad, en el que transita de la pretendida modernidad republicana a los lugares de la reunión comunitaria del pueblo. El viaje del héroe culmina en un lugar propicio para trabajar el conflicto. Son lugares que, aunque no tengan referencia en la realidad, sí aluden a ella. Son espacios míticos, como el pueblo de El coronel no tiene quien le escriba. Ahí, se ponen en juego las relaciones entre la historia y el mito, entre el tiempo lineal y el circular, en el que se presentan todos los tiempos. Son los lugares donde los héroes experimentan una situación conflictiva que desencadena la discusión de ideas propia de la polifonía.

El conflicto del héroe está enmarcado entre las necesidades del cuerpo y su posposición por la predominancia de los discursos ajenos, que desimbolizan las esferas organizadoras del mundo de la vida, como la política, la social y la religiosa, dado el accidentado transcurso de los paradigmas históricos implantados en Latinoamérica. Se trata de héroes escindidos e inacabados con los cuales puede identificarse el lector, mediante la simpatía, la ironía, la admiración, el asombro, la conmoción, etc. En este sentido, la fidelidad a los textos requiere de la lectura al modo del mito para realizar un acto posibilitador de una consecuencia ética, como la que pro- 
pone la teoría de la recepción desarrollada por Jauss. La obra deja abierta la posibilidad de la resimbolización de las estructuras y los discursos que se generan en las relaciones humanas con los otros y con lo otro.

Un acercamiento hermenéutico a la novela El coronel no tiene quien le escriba nos invita a fijar la atención en la simbolización comunitaria en la que las acciones en torno al gallo de pelea cobran un significado ritual de solidaridad entre los integrantes de una comunidad oprimida por una parodia de la república moderna. Ya el título de la novela anuncia las líneas de una estructura antitética de la historia de este relato.

En efecto, la trama de la novela transcurre en una creciente tensión entre el mundo de la modernidad latinoamericana, de la cultura de la escritura, y el mundo de la tradición, de la oralidad, que culmina en la resolución de esta lucha presente en la interioridad del personaje del coronel, un hombre que pasó su vida creyendo en y trabajando por los ideales de la república moderna y que en el momento de su vejez debate sus convicciones entre estos dos mundos.

A partir de la cotidianidad, que marca el tono del relato, empieza el recorrido del coronel en su debate interior. Las escenas del inicio adentran al lector en los contextos y los personajes de la antítesis en la que se desarrolla la historia del personaje.

La dinámica del relato conduce al coronel de la modernidad decadente a una renovada modernidad en la que emergen como fuerzas liberadoras las tradiciones relegadas por la primera. La comunidad de los habitantes del pueblo se realiza alrededor del mantenimiento del gallo como símbolo de la renovación. Por ello, el dilema del coronel frente a la venta del animal, nada menos que al cacique Don Sabas, fiel representante de la parodia republicana, se convierte en una lucha decisiva en relación con el enfrentamiento de su realidad y las consecuencias de desencanto de sus incursiones por el mundo de la modernidad.

Frente a este mundo de la modernidad, en el pueblo se desarrolla otra forma de comunicación, de construcción y mantenimiento de valores, que se realiza a través de rituales como el de la ceremonia de entierro del muerto, en la que mediante los ritos como el 
tapizado de flores de las calles, la reunión en el velorio y la marcha hacia el cementerio acompañada por la banda de músicos, se consolidan sus convicciones como pueblo al que la modernidad no le ha cumplido sus promesas. De esta manera, las ceremonias que se dirigen al muerto contribuyen a la reunión de los vivos y constituyen el primer indicio manifiesto en el coronel de vuelta de su mirada de su regreso hacia las tradiciones comunitarias: "Al desembocar a la calle central sufrió un estremecimiento. Hasta donde alcanzaba su vista el pueblo estaba tapizado de flores. Sentadas a la puerta de las casas las mujeres de negro esperaban el entierro" (12-13). Por otra parte, la escritura en el uso comunitario cobra el valor de la comunicación desde la clandestinidad, a través de hojas de denuncia. De esta manera, se subvierten los usos modernos de la cultura de la escritura, por ejemplo el de la "veracidad informativa» de los periódicos. Es el mismo caso de la pelea de gallos, que para los usos modernos es un lugar de juego, mientras que para la tradición simboliza un lugar de renovación de los lazos comunitarios. Por esta razón, el gallo cobra especial significación para el coronel, ya que es la herencia recibida por la nueva generación, esto es, de las manos de su hijo, presuntamente asesinado durante una redada en la gallera, lugar de reunión política también. Esta circunstancia provoca un acercamiento del coronel a esa otra lucha, la clandestina, la del pueblo joven, tan distinta de la suya en el mundo de la burocracia en el que culminó su actividad de juventud, tan parecida a la de los jóvenes como su hijo.

Así, el recorrido del coronel culmina en la gallera, con una toma de conciencia provocada por la captación plena del significado de la reunión:

Examinó la galería circular impulsado por una curiosidad un poco despreciativa. Una multitud exaltada se precipitó por las graderías hacia la pista. El coronel observó la confusión de rostros cálidos, ansiosos, terriblemente vivos. Era gente nueva. Toda la gente nueva del pueblo. Revivió -como en un presagio- un instante borrado en el horizonte de su memoria. (109) 
El desenlace, si no optimista, es liberador al darse la circunstancia de que el coronel es ganado por una toma de conciencia que nos deja, como lectores, en la perspectiva abierta a la interpretación de la última palabra que pronuncia el coronel al concluir el texto:

La mujer se desesperó.

"Y mientras tanto qué comemos", preguntó, y agarró al coronel por el cuello de la franela. Lo sacudió con energía.

-Dime, qué comemos.

El coronel necesitó setenta y cinco años, los setenta y cinco años de su vida, minuto a minuto para llegar a ese instante. Se sintió puro, explícito, invencible, en el momento de responder:

-Mierda. (121)

\section{Conclusión}

En la novela de García Márquez observamos el trayecto de un héroe, cuyos conflictos ponen en el plano de la discusión ideas reveladoras de un significado simbólico que, aunque no se resuelve en el plano del relato, sí deja abierta la discusión mediante un discurso sugerente, sobre el cual el lector puede continuar la reflexión.

En El coronel no tiene quien le escriba, a partir del recorrido interno del personaje hacia la resolución de la propia identidad, en medio de la modernidad y de la tradición, el receptor que lo acompaña tiene la posibilidad de realizar una identificación ${ }^{2}$ de efecto liberador al tener el privilegio de saber más que el personaje del coronel

${ }^{2}$ En su teoría de la recepción estética, Jauss describe cinco tipos de identificación con el héroe:

1. Asociativa, la cual se suscita en una relación de representación comunitaria como el juego, la lucha, la fiesta. Este tipo de relación provoca una disposición receptiva de asunción de funciones propias de estas representaciones. La clase de comportamiento receptivo que se puede dar en el participante es de tipo regresivo si la identificación provoca el exceso sin la reflexión, o de tipo progresivo si la sociabilidad provoca el sentimiento de libertad. 
en el tratamiento de las situaciones y de los personajes y, por lo tanto, de desplegar una identificación irónica respecto de los personajes y las situaciones de la modernidad disonante, en contraste con una identificación asociativa al asumir el sentido liberador de los rituales colectivos de los personajes y las situaciones de la tradición.

Estos tipos de identificación del lector con los personajes y las situaciones del relato tendrán un desenlace progresivo si en el caso de los rituales tradicionales el lector capta la manera en que resaltan como alternativa frente a la decadencia de los ideales no logrados de la modernidad y, por otra parte, si la ironía con la que el narrador trata a los personajes de la modernidad es percibida por el lector como una manifestación de decadencia de un modelo de vida que no prosperó en la comunidad. En el texto analizado, el autor redime a sus personajes focales, con lo cual expresa una posición liberadora, de compasión hacia ellos.

La narrativa de García Márquez surge en un contexto similar al que señala Bajtín para la novela polifónica, es decir en un contexto en el que el univocismo se implanta en sociedades que conservan

2. Admirativa, que se suscita en una relación con un héroes total, lo cual provoca una disposición receptiva de admiración, con comportamiento regresivo si da paso a una imitación acrítica o un alejamiento evasivo, o con un comportamiento progresivo si da paso a la emulación del ejemplo.

3. Simpatética, que se suscita ante el héroe imperfecto, cotidiano, provocando una disposición receptiva de compasión, con comportamiento regresivo si se limita al sentimentalismo que autoconfirma al propio receptor, o progresivo si despierta un interés moral y la solidaridad.

4. Catártica, que se presenta ante el héroe sufriente u oprimido, al crear una disposición receptiva de conmoción trágica o de risa participadota. Provoca un comportamiento regresivo si sólo despierta curiosidad y burla, o un comportamiento progresivo si da lugar a un interés que promueva la reflexión libre o juicio moral libre.

5. Irónica, que se presenta ante el héroe desaparecido o el antihéroe, lo cual provoca una disposición receptiva de extrañeza provocativa, con un comportamiento regresivo si conduce al solipsismo, el aburrimiento o la indiferencia, y un comportamiento progresivo si despierta la creatividad, la sensibilización de la percepción y la reflexión crítica. 
su carácter tradicional. La polifonía hace emerger estas voces reprimidas. La lectura resulta así desideologizadora, en tanto que provoca la caída de un mito, pero también restauradora del sentido cuando revela otros sentidos míticos subyacentes.

\section{Bibliografía}

Bajtín, Mijaíl. Problemas de la poética de Dostoievski. Tr. Tatiana Bubnova. México: FCE, 1988.

Gadamer, Hans-Georg. Mito y razón. Tr. José Francisco Zúñiga García. Barcelona: Paidós, 1977. Verdad y método I. Tr. Manuel Olasagasti. Salamanca: Ediciones Sígueme, 1977.

García Márquez, Gabriel. El coronel no tiene quien le escriba. Barcelona: Plaza \& Janés, 1974.

Hernández Alvídrez, Elizabeth. Hermenéutica, educación y analogía. Fundamentos hermenéuticos de una educación mediante la lectura de textos literarios. México: UPN, 2004.

Jauss, Hans Robert. Experiencia estética y hermenéutica literaria. Tr. Jaime Siles y Ela Fernández. Madrid: Taurus, 1999.

Rama, Ángel. Transculturación narrativa en América Latina. México: Siglo XXI, 1992.

Ricoeur, Paul. Del texto a la acción. Ensayos de hermenéutica II. Tr. Pablo Corona. México: FCE, 2001.

—. La lectura del tiempo pasado: memoria y olvido. Madrid: Arrecife/UAM, 1999. 1995. . Tiempo y narración I. Tr. Agustín Neira. México: Siglo XXI, 